\title{
Interaction of Methylmercury and Selenium on the Bioaccumulation and Histopathology in Medaka (Oryzias latipes)
}

\author{
Chun-Yang Liao, Qun-Fang Zhou, Jian-Jie Fu, Jian-Bo Shi, Chun-Gang Yuan, \\ Gui-Bin Jiang \\ State Key Laboratory of Environmental Chemistry and Ecotoxicology, \\ Research Center for Eco-Environmental Sciences, Chinese Academy of Sciences, \\ P.O. Box 2871, Beijing 100085, China
}

Received 17 December 2005; revised 18 May 2006; accepted 23 September 2006

\begin{abstract}
Interaction of methylmercury and selenium in medaka (Oryzias latipes) on bioaccumulation of pollutants and histopathological changes in liver and gill were studied. Juvenile medaka fish were submitted to a series of waterborne methylmercury chloride (MMC), sodium selenite $\left(\mathrm{Na}_{2} \mathrm{SeO}_{3}\right)$ and their mixture for 210 days, respectively. The methylmercury $(\mathrm{MeHg})$ and selenium contents in the whole body of medaka were determined. The dose- and time-dependent increase of $\mathrm{MeHg}$ and selenium contents in medaka were observed. Histopathological changes, such as edema, vacuoles, pyknotic nucleus, and telangiectasis, could clearly be observed in the slices from the exposed medaka's liver and gill. Concurrent exposure to MMC and $\mathrm{Na}_{2} \mathrm{SeO}_{3}$ showed the increased selenium accumulation. When the exposure molar ratio of MeHg:Se was about 1 , the interaction between $\mathrm{MeHg}$ and selenium offered a limited protection against the serious intoxication of both $\mathrm{MMC}$ and $\mathrm{Na}_{2} \mathrm{SeO}_{3}$ to medaka. (c) 2007 Wiley Periodicals, Inc. Environ Toxicol 22: 69-77, 2007.
\end{abstract}

Keywords: medaka; methylmercury; sodium selenite; bioaccumulation; histopathology

\section{INTRODUCTION}

Mercury is a highly toxic heavy metal element. Owing to its specific physicochemical property, mercury and its relevant products are widely used in industry and agriculture, which has caused many serious environmental problems (Donangelo and Dorea, 1998; Kondo, 2000; NRC, 2000; Dolbec et al., 2001). Among mercury species, organic forms, especially methylmercury ( $\mathrm{MeHg}$ ), are by far considered to be more toxic to organisms than inorganic forms. $\mathrm{MeHg}$ is bioavailable to aquatic organisms (Inza et al., 1998; Hammerschmidt et al., 2002) and can be biomagnified through the food chain, thus

Correspondence to: G.-B. Jiang; e-mail: gbjiang@rcees.ac.cn

Contract grant sponsor: Chinese Academy of Sciences.

Contract grant sponsor: National Basic Research Program of China.

Contract grant sponsor: National Natural Science Foundation of China.

Contract grant number: KJCX2-SW-H06, 2003CB415001, 20137010.

Published online in Wiley InterScience (www.interscience.wiley.com). DOI 10.1002/tox.20236 affecting human health (Lebel et al., 1998; Myers et al., 2000). Investigations on uptake, accumulation, biotransformation, and excretion of $\mathrm{MeHg}$ in fish are available to exemplify their effects on specific systems (Heath, 1995). Although much attention has been paid to $\mathrm{MeHg}$ intoxication (Baatrup, 1991; Heath, 1995; Berntssen et al., 2003), relatively few investigations have been performed on long-term exposure of juvenile fish to low levels of $\mathrm{MeHg}$ relevant to environmental contamination. Compared to the adult, the juvenile is usually thought to be more susceptible to environmental contaminants (Houck and Cech, 2004).

Selenium is an indispensable trace element, and plays an important role as part of the active site in selenoproteins, such as glutathione peroxidase, in organisms. Selenium can antagonize the toxicities of various heavy metals by complex interaction mechanisms in organism. Nevertheless, superfluous selenium accumulated in animals also restrains some physiological oxidation process, accordingly inhibiting the activities of diverse enzymes and thiol-containing amino acids (Hilton et al., 1980). Excessive intake of selenium can lead to loss of hair and nails, vomiting, nausea, nerve damage, skin rashes, bad breath, brittle 
bones, and so on (Xu and Fan, 1991). For rats, the lethal dose of sodium selenite is $5.5 \mathrm{mg} / \mathrm{kg}$ by intraperitoneal dosing, which is comparative to the toxicity of methylmercury chloride (MMC, $\mathrm{LD}_{50} 11 \mathrm{mg} / \mathrm{kg}$ ) (MSDS, 2004).

Early in 1970s, it was found that marine mammals could accumulate exceptionally high concentrations of mercury and selenium compounds without obvious intoxication symptoms (Koeman et al., 1973), which showed that the interaction between mercury and selenium might exist to weaken the toxicities of both chemicals. The mutual interaction between mercury and selenium differs from species to species (Cuvin-Aralar and Furness, 1991), mainly relying on their molar ratios (Komsta-Szumska and Chmielnicka, 1977; Cuvin-Aralar and Furness, 1991). Koeman et al. (1973) first found a molar ratio of $1: 1$ between mercury and selenium in dolphin and seal that could significantly reduce toxic effects induced by the single pollutant. Aoshima and Kasuya (1980) observed that the toxicity was low for cultured rat cerebrum exposed to 10:1 of mercuric chloride and sodium selenite. Wang et al. (2001) suggested that the exposure of $\mathrm{Hg}: \mathrm{Se}$ with the molar ratio lower than 1:2 could do harm to cultured Atlantic spotted dolphin renal cell by the measurement of cell growth and apoptosis frequency, while $\mathrm{Hg}$ :Se molar ratio of 1:4 had no harmful effects. According to a survey on mercury and selenium contents in 39 types of seafood collected in Modena of Italy, it was found that different molar ratios of mercury:selenium exist in different organisms, such as 0.23 for fish, 0.09 for shellfish, 0.81 for swordfish, 0.80 for grayfish, and 0.75 for perch, which might show that various action mechanisms could occur in biota.

Although interaction of mercury with selenium has been studied for long periods, the mechanism is not yet fully understood (Cuvin-Aralar and Furness, 1991), especially in fish such as medaka (Oryzias latipes). Selenium is usually thought to be able to resist mercury's toxicity, and the high toxicity of excessive selenium is seldom paid attention to (Xu and Fan, 1991). Concurrent exposure is worth to be carried out to study the interaction between mercury and selenium. The accumulation of methylmercury and selenium, with particular emphasis on impairment and lesions of liver and gill tissues by morphological observation, interaction between methylmercury and selenium, and the corresponding toxic effects in it is to be studied herein by the 210day's exposure test under low levels of MMC and sodium selenite, using medaka as the experimental model.

\section{MATERIALS AND METHODS}

\section{Experimental Fish}

A batch of 10-day old juvenile medaka with the mean value of $5.61 \mathrm{~mm}$ in body length and $0.85 \mathrm{mg}$ in mass were used in concurrent exposure to methylmercury chloride (MMC) and sodium selenite $\left(\mathrm{Na}_{2} \mathrm{SeO}_{3}\right)$. The test fish were preraised in a flow-through system, continuously supplied with the water that was dechlorinated by activated charcoal filters and constantly aerated. The water qualities were controlled as follows: $\mathrm{pH}, 6.9-7.9$; oxygen concentration, 5-7 mg/L; hardness of $\mathrm{CaCO}_{3}, 250 \mathrm{mg} / \mathrm{L}$; conductivity, $650 \mu \mathrm{S} / \mathrm{cm}$; water temperature, $22.5-25.5^{\circ} \mathrm{C}$. The fishes were fed twice a day with a commercial ration of artemia hatched daily and kept under a 12/12 h of light/dark cycle.

\section{Reagents}

Appropriate amount of MMC (98\%, Merck-Schuchardt) and sodium selenite $\left(\mathrm{Na}_{2} \mathrm{SeO}_{3}, 98 \%\right.$, Beijing Zhonglian Chemical Company) were dissolved respectively in methanol and deionized water to give stock solutions of $1 \mathrm{mg} \mathrm{Hg} /$ $\mathrm{mL}$ and $3.936 \mathrm{mg} \mathrm{Se} / \mathrm{mL}$, which were maintained in a sealed brown volumetric flask at $4{ }^{\circ} \mathrm{C}$. The working solutions $(1 \mu \mathrm{g} \mathrm{Hg} / \mathrm{mL}$ and $3.936 \mu \mathrm{g} \mathrm{Se} / \mathrm{mL})$ were freshly prepared by the dilution of the stock solution with deionized water just before use.

Ninety grams of $\mathrm{KBr}$ was dissolved in $100 \mathrm{~mL}$ water, and $25 \mathrm{~mL}$ concentrated $\mathrm{H}_{2} \mathrm{SO}_{4}$ was added to $50 \mathrm{~mL}$ water. After cooling to room temperature, the two solutions were mixed and diluted to $500 \mathrm{~mL}$ with Milli-Q water, giving the acidic potassium bromide solution.

One mol per liter of $\mathrm{CuSO}_{4}$ solution and $0.01 \mathrm{~mol} / \mathrm{L}^{-1}$ $\mathrm{Na}_{2} \mathrm{~S}_{2} \mathrm{O}_{3}$ solution were prepared by dissolving $25 \mathrm{~g}$ of $\mathrm{CuSO}_{4} \cdot 5 \mathrm{H}_{2} \mathrm{O}$ and $0.2482 \mathrm{~g} \mathrm{Na}_{2} \mathrm{~S}_{2} \mathrm{O}_{3} \cdot 5 \mathrm{H}_{2} \mathrm{O}$ separately in $100 \mathrm{~mL}$ water and stored at $4^{\circ} \mathrm{C}$.

All other reagents used were of analytical grade or better.

\section{Exposure Treatment Design}

The exposure experiment was carried out by static aquatic solution for 210 days. Fishes were placed in 14-L glass aquaria (80 fishes per aquarium). Half of the exposure solution was renewed per day in each treatment. The MMC concentrations were set as $0,0.01,0.1,1 \mathrm{ng} \mathrm{Hg} / \mathrm{mL}$ (named by groups control, $\mathrm{Hg}$-I, Hg-II, Hg-III), which were chosen based on the mercury level in some typical rivers of China (Wu et al., 1994). Based on the molar ratios of 1:1, 1:5, and 1:10 between $\mathrm{Hg}$ and $\mathrm{Se}$, the exposure concentrations of sodium selenium $\left(\mathrm{Na}_{2} \mathrm{SeO}_{3}\right)$ were set as 0.3936, 1.968, $3.936 \mathrm{ng} \mathrm{Se} / \mathrm{mL}$ (groups Se-I, Se-II, Se-III), and the concurrent exposures were $1 \mathrm{ng} \mathrm{Hg} / \mathrm{mL}+$ $0.3936 \mathrm{ng} \mathrm{Se} / \mathrm{mL}, 1 \mathrm{ng} \mathrm{Hg} / \mathrm{mL}+1.968 \mathrm{ng} \mathrm{Se} / \mathrm{mL}, 1 \mathrm{ng} \mathrm{Hg} /$ $\mathrm{mL}+3.936 \mathrm{ng} \mathrm{Se} / \mathrm{mL}$ (groups MS-I, MS-II, MS-III), respectively. Ten fishes were sampled on day 150, 180, and 210 for each treatment, which were called by sampling 1, 2, and 3, wherein, samples from sampling 1 and 2 were used for chemical analysis, and specimen from sampling 3 was used for histological studies.

\section{Methylmercury Content Analysis}

$\mathrm{MeHg}$ content was detected by a GC-AFS hyphenation system, which has been proved to be available for speciation analysis of mercury compounds (Shi et al., 2005). Three of the fish were randomly chosen for $\mathrm{MeHg}$ analysis. The 
sample preparation was based on the previous method (Alli et al., 1994; Cai et al., 1997) with slight modification. Briefly, about $0.1-0.2 \mathrm{~g}$ of whole body from a medaka fish was weighed in triplicates, and then homogenized and put into a $50 \mathrm{~mL}$ glass centrifuge tube. Five milliliters of Milli$\mathrm{Q}$ water and $4 \mathrm{~mL}$ of acidic $\mathrm{KBr} / \mathrm{CuSO}_{4}$ (3:1 ratio) solution were added in sequence. The tube was mechanically shaken overnight, and then $6 \mathrm{~mL}$ of $\mathrm{CH}_{2} \mathrm{Cl}_{2}$ was added and shaken for another $1 \mathrm{~h}$ to extract organomercury compounds. After centrifugation at $2000 \mathrm{rpm}$ for $10 \mathrm{~min}$, the $\mathrm{CH}_{2} \mathrm{Cl}_{2}$ phase (4 mL) was transferred into a $10 \mathrm{~mL}$ glass tube and extracted with $1 \mathrm{~mL}$ of $\mathrm{Na}_{2} \mathrm{~S}_{2} \mathrm{O}_{3}$ solution $(0.01 \mathrm{~mol} / \mathrm{L})$. After shaking for $45 \mathrm{~min}$, the solution was left for phase separation. Aqueous phase $(0.6-0.8 \mathrm{~mL})$ was pipetted and transferred into a $3 \mathrm{~mL}$ microcentrifuge tube. Then $0.3 \mathrm{~mL}$ of acidic $\mathrm{KBr} / \mathrm{CuSO}_{4}$ solution (3:1 ratio) and $0.5 \mathrm{~mL}$ of $\mathrm{CH}_{2} \mathrm{Cl}_{2}$ were added. The mixtures were shaken rapidly for $30 \mathrm{~min}$ and centrifuged for $15 \mathrm{~min}$ at $5000 \mathrm{rpm}$. The lower solvent layer was removed by micropipette and transferred to a $1 \mathrm{~mL}$ clean screw cap glass vial, via a $\mathrm{Na}_{2} \mathrm{SO}_{4}$ drier tube. The organomercury compounds in solutions were then separated and determined by GC-AFS. Reagent blanks were processed simultaneously to deduct the error induced by analytical procedure. The certified reference material DORM-2 (Dogfish muscle) was analyzed to validate the method, and the obtained result $(4250 \pm 184 \mathrm{ng} / \mathrm{g}$, mean \pm $\mathrm{SD}, n=4)$ proved to be in good agreement with the certified value $(4470 \pm 320 \mathrm{ng} / \mathrm{g})$.

\section{Selenium Content Analysis}

Selenium content was detected following the modification of the published method (He et al., 2002). In brief, about 0.1-0.2 $\mathrm{g}$ of homogenate tissues were weighed in triplicates and then put into a PTFE digestion container. Two milliliters of concentrated $\mathrm{HNO}_{3}$ was added, and the containers were sealed and left to predigest overnight on an electrothermal hotplate at $60^{\circ} \mathrm{C}$. After cooling, $1 \mathrm{~mL}$ of $\mathrm{H}_{2} \mathrm{O}_{2}$ (30\%) was added into the containers, which were thereafter placed in stainless steel bombs and sealed with a screw closure to avoid any acid leakage, and placed in an oven heated at $160^{\circ} \mathrm{C}$ for $6 \mathrm{~h}$. After cooling to ambient temperature, the solutions were completely transferred into a PET bottle and diluted to $10 \mathrm{~mL}$ with Milli-Q water. Four milliliters of the solution was transferred into a tube. Se was reduced to $\mathrm{Se}^{\mathrm{IV}}$ by adding $4 \mathrm{~mL}$ of concentrated $\mathrm{HCl}$ and kept at $90^{\circ} \mathrm{C}$ for $30 \mathrm{~min}$. The resulting solution was diluted to $10 \mathrm{~mL}$ with Milli-Q water and then detected by an AF-620 nondispersive atomic fluorescence spectrophotometer (AFS, Beijing Ruili Analytical Instrument, Beijing, China) after hydride generation. The optimized experimental parameters for AFS were listed in Table I. Reagent blanks were processed simultaneously to deduct the error induced by analytical procedure. The determination of $\mathrm{Se}$ was
TABLE I. Optimized experimental conditions for AFS

\begin{tabular}{ll}
\hline Parameters & \multicolumn{1}{c}{ Optimized Values } \\
\hline Hydride generation & \\
$\mathrm{KBH}_{4}$ concentration & $2.0 \%(\mathrm{~m} / \mathrm{v})$ \\
$\mathrm{HCl}$ concentration & $1.2 \mathrm{~mol} / \mathrm{L}$ \\
Sampling time & $5 \mathrm{~s}$ \\
Hydride generation time & $22 \mathrm{~s}$ \\
AFS & \\
Lamp & Hollow cathode lamp, $196.0 \mathrm{~nm}$ \\
PMT voltage & $320 \mathrm{~V}$ \\
Primary current & $60 \mathrm{~mA}$ \\
Carrier gas & Argon, $400 \mathrm{~mL} / \mathrm{min}$ \\
\hline
\end{tabular}

performed in the certified reference material prawn GBW08572 to validate the method, and the result $(1.56 \pm$ $0.04 \mu \mathrm{g} / \mathrm{g}$, mean $\pm \mathrm{SD}, n=3$ ) agreed well with the certified value $(1.52 \pm 0.02 \mu \mathrm{g} / \mathrm{g})$.

\section{Histological Study}

The liver and gill of medaka were collected in duplicate from the control, Hg-I, Hg-III, Se-I, Se-III, MS-I, MS-II, and MS-III groups. Tissues were fixed in $10 \%$ neutral buffered formalin, then washed and dehydrated with a graded ethanol series, and embedded in paraffin blocks. Serial 4-5$\mu \mathrm{m}$ sections were cut from the block samples and stained with hematoxylin and eosin (H\&E), then observed and photographed under light microscope (OLYMPUS BX41TF, Japan).

\section{Statistical Analysis}

The results were expressed as means \pm SDs. Statistical differences $(P<0.05)$ between the groups were determined by one-way analysis of variance.

\section{RESULTS AND DISCUSSION}

\section{Behavior Observation}

During the whole experiment procedure, the routine behavior, including swimming, breath, prey development and death, etc., was observed carefully to evaluate the effects induced by the chemicals. The control fish displayed normal living behavior. They preyed artemia rapidly, and their body color showed brilliant orange red, when compared with the exposed fish. In the exposure groups, no obvious differences were found in breathing and swimming behaviors when compared with the control by visual observation. Similar intake modes, development, body color and size, and breathing and swimming behaviors existed in the 
TABLE II. The mortality rate and number of vertebral abnormality in each group

\begin{tabular}{lll}
\hline Group & $\begin{array}{c}\text { Mortality } \\
\text { Rate }(\%)\end{array}$ & $\begin{array}{c}\text { Number of Vertebral } \\
\text { Abnormality }\end{array}$ \\
\hline Control & 12.5 & 0 \\
Hg-I & 15 & 1 (slightly) \\
Hg-II & 25 & 2 \\
Hg-III & 36.25 & 3 \\
Se-I & 36.25 & 1 (slightly) \\
Se-II & 15 & 1 \\
Se-III & 38.75 & 1 \\
MS-I & 25 & 5 \\
MS-II & 28.75 & 2 (slightly) \\
MS-III & 21.25 & 2 \\
\hline
\end{tabular}

exposed fish, regardless of the single $\mathrm{Hg}$, single $\mathrm{Se}$, or concurrent exposure (MS) groups, except the MS-I group $(P<$ $0.05, n=20)$. The reproduction performances of the exposed fish might be inhibited to a certain degree, because their spawning amounts were somewhat less than those of the control fish. In general, several indexes of fish from the MS-I group were similar to those of the control, except mortality and developmental abnormality (bent spine) rate $(P<0.05, n=26)$.

As shown in Table II, different degree of mortality and bent spine rate were observed in medaka. For the single $\mathrm{Hg}$ exposure groups, the fish's mortality was up to $36.25 \%$ and clearly increased with the increase of MMC dose $(P<$ $0.05, n=26$ ), indicating that even trace levels of MMC administration could also lead to medaka's severe intoxication, including death after a long duration. For the single Se groups, the mortality was basically higher than those of the single $\mathrm{Hg}$ groups because ofthe high doses of $\mathrm{Na}_{2} \mathrm{SeO}_{3}$, which exteriorly proved high toxicity of $\mathrm{Na}_{2} \mathrm{SeO}_{3}$. For the MS groups, because the interaction of $\mathrm{MeHg}$ with selenium, the mortalities were slightly lower than those of the highest dose of the single $\mathrm{Hg}$ and Se groups. Vertebral abnormality of fish was common in the exposed groups. For the single $\mathrm{Hg}$ groups, because of the high toxicity of $\mathrm{MeHg}$, the deformation was somewhat severe, both in number and degree when compared with the single Se groups. For the single Se groups, abnormality case was less serious. This might be due in part to lower developmental abnormality effect of selenium. For the MS groups, the abnormality status was serious because of highly combined toxicity of mercury and selenium. Surprisingly, the deformation in the MS-I group was especially severe. As observed in the liver slice stated later, no obvious histopathological changes existed in hepatocytes of the MS-I group because of the interaction of selenium with $\mathrm{MeHg}$. The interaction, however, could not withstand against developmental abnormality action, which was potentially because the interaction between mercury and selenium provided protection de- pending on many factors such as administration order and toxic action occurring sites (Xu and Fan, 1991). It seemed inexplicable and needed further investigation.

\section{Accumulation of Methylmercury and Selenium in Medaka}

High levels of methylmercury, ranging from 48.05 to $2430.50 \mathrm{ng} \mathrm{Hg} / \mathrm{g}$ (wet weight), were detected in MMCtreated groups. No organic mercury compounds in other forms were detected in these samples by using the GC-AFS system designed for mercury speciation analysis. Figure 1 showed $\mathrm{MeHg}$ concentrations in whole bodies of medaka from two samplings, after low-levels of MMC administration for long-term. In the single $\mathrm{Hg}$ exposure groups (Hg-I, II, and III), an obvious dose-related increase was found in both sampling 1 and $2(P<0.01, n=3)$. Meanwhile, $\mathrm{MeHg}$ contents in the concurrent exposure groups (MS-I, II, and III) were similar to those in the $\mathrm{Hg}$-III group for both samplings, because the administered doses of MMC in the MS groups were the same as that in the $\mathrm{Hg}$-III group. This indicated that increasing the dose of $\mathrm{Na}_{2} \mathrm{SeO}_{3}$ could not give significant effect on $\mathrm{MeHg}$ accumulation according to Figure $1(P>0.05, n=3)$. A time-dependent increase of $\mathrm{MeHg}$ contents was observed in each group, except the Hg-I group for sampling 1 and $2(P<0.05$, $n=3$ ).

Selenium contents in whole bodies of medaka from the $\mathrm{Na}_{2} \mathrm{SeO}_{3}$-treated groups were in the range of 39.06$1314.92 \mathrm{ng} \mathrm{Se} / \mathrm{g}$ (wet weight) and actually increased with the exposure time. Figure 2 showed the Se contents in the whole bodies of medaka from two times' samplings. In the single Se exposure groups (Se-I, II, and III), the Se contents accumulated in medaka slightly increased with the

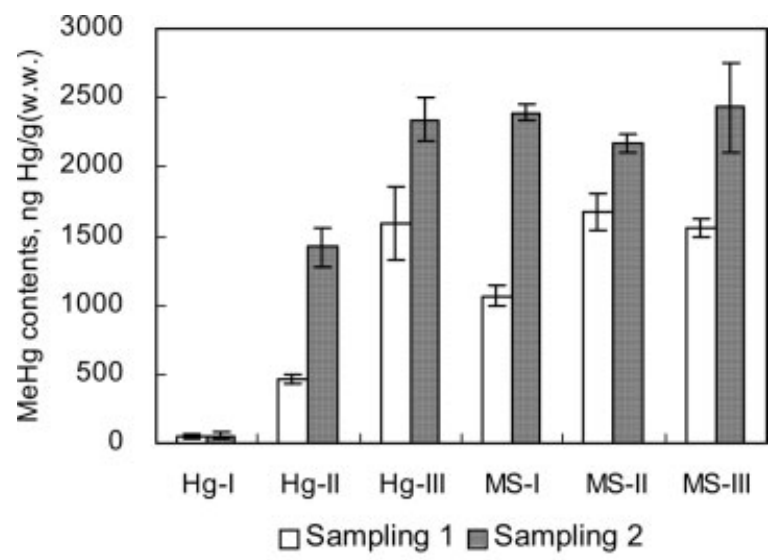

Treatment

Fig. 1. MeHg contents in the whole body of medaka from two times' samplings (mean $\pm \mathrm{SD}, n=3$ ), $\mathrm{ng} \mathrm{Hg} / \mathrm{g}$ (wet weight). 


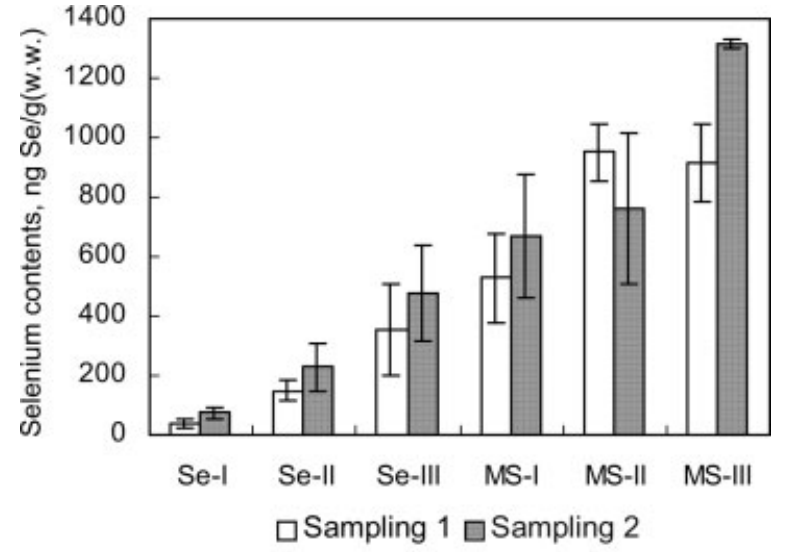

Treatment

Fig. 2. Selenium contents in the whole body of medaka from two times' samplings (mean $\pm \mathrm{SD}, n=3$ ), ng Se/g (wet weight).

administration doses of $\mathrm{Na}_{2} \mathrm{SeO}_{3}$ for both sampling 1 and 2. In contrast to the $\mathrm{MeHg}$ accumulation in medaka, $\mathrm{Se}$ contents in the MS groups were generally higher than those in the corresponding single Se groups and were also dosedependent for both samplings (for example, increase between the MS-II and MS-III groups, $P<0.05, n=3$ ). As well known, high mercury concentrations may induce parallel selenium accumulation to detoxify the mercury (Goede and Wolterbeek, 1994). It is accessible that the selenium accumulation in MS groups would increase with administration of MMC. Anyway, the present results proved that the concurrent exposure to $\mathrm{MMC}$ and $\mathrm{Na}_{2} \mathrm{SeO}_{3}$ could not significantly influence the $\mathrm{MeHg}$ accumulation, but effectively promoted selenium accumulation in medaka body after a long exposure period.

\section{Molar Ratios Between Methylmercury and Selenium}

Increase of mercury and selenium in medaka with time was common to both the single and concurrent exposure groups (for example, in the MS-III group, $P<0.05, n=3$ ). In this paper, the molar ratio was defined as $\mathrm{MeHg}$ :selenium (signed as $\mathrm{Hg}: \mathrm{Se}$ in Fig. 3). Figure 3 showed the molar ratio of $\mathrm{MeHg}$ and selenium accumulated in medaka body. The $\mathrm{Hg}$ :Se molar ratios of the sampling 2 were all larger than those of the sampling 1, indicating that the uptake of $\mathrm{MeHg}$ was fast when compared with that of selenium. When administrating both chemicals, the selenium in medaka from three concurrent exposure groups generally increased (for example, increase from MS-II to MS-III, $P<0.05, n=$ 3) while $\mathrm{MeHg}$ kept constant owing to the equivalent dose of MMC in the three groups. And accordingly, the $\mathrm{Hg}: \mathrm{Se}$ molar ratio decreased from MS-I to MS-III with a small amplitude, which suggested selenium be elevated with the
$\mathrm{MeHg}$ for withstanding against both toxicities. However, according to the histopathological observation in medaka's liver and gill, the interaction between $\mathrm{MMC}$ and $\mathrm{Na}_{2} \mathrm{SeO}_{3}$ offering protection only occurred in the MS-I group but not in the MS-II and MS-III groups. This suggested that the interaction presents a limited protection against intoxication of both $\mathrm{MMC}$ and $\mathrm{Na}_{2} \mathrm{SeO}_{3}$ in medaka.

\section{Histological Observation}

Slices of the control group show no abnormalities in liver and gill of medaka. Morphological changes are observed in tissues of exposed fishes. Herein, morphological changes of two tissues in fish after 7 months of exposure were taken as examples for observation. The incidence of the lesions is described in detail as follows.

I. Liver: The liver section from the control group showed normal gross structure and homogeneous cytoplasm without edema, vacuolation, or necrosis [Fig. 4(a)]. However, varying degrees of histopathological changes, such as edema, vacuoles, and pyknotic nucleus, were clearly observed in hepatocytes from the single $\mathrm{Hg}$, single $\mathrm{Se}$, and $\mathrm{MS}$ groups. For the single $\mathrm{Hg}$ exposure groups after 7 months' treatment with MMC, the liver tissues of exposed medaka were softer and more friable than the normal. Since the cytoplasm of hepatocyte became basophilic, the liver section turned to gray, which indicated slight hepatocellular lesions. Concurrently, severe hepatocellular lesions such as edema and vacuole were common to hepatocytes, and the vacuoles increased in number and size with administration doses of MMC. Furthermore, even pyknotic nucleus was also found in the Hg-III group [Fig. 4(b)]. On the whole, the hepatocellular lesion was dose-dependent. Similar trend was observed in the single Se groups, and Figure 4(c)

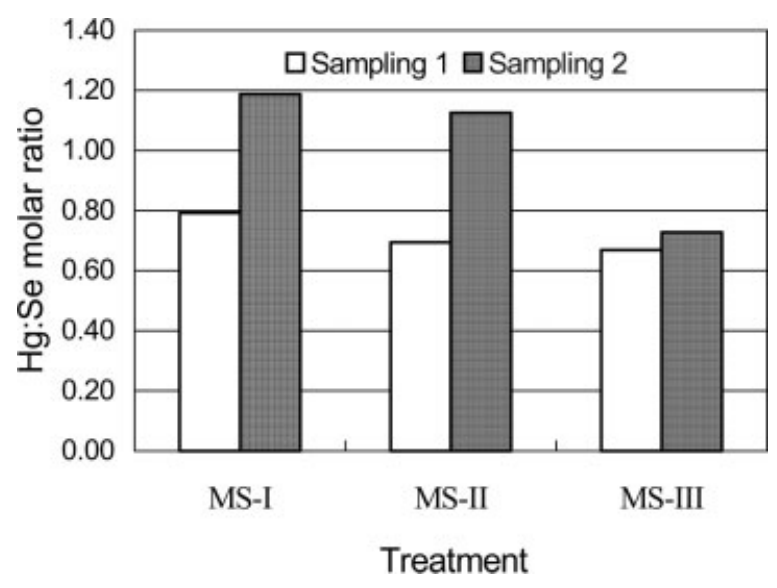

Fig. 3. The molar ratios between methylmercury and selenium in medaka from the concurrent exposure groups of sampling 1 and 2 . 


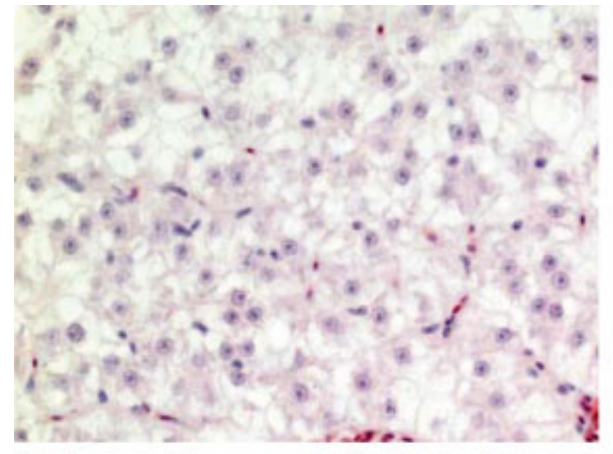

(a)

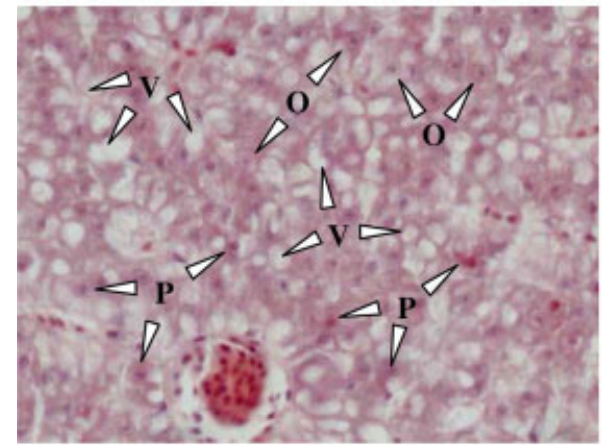

(c)

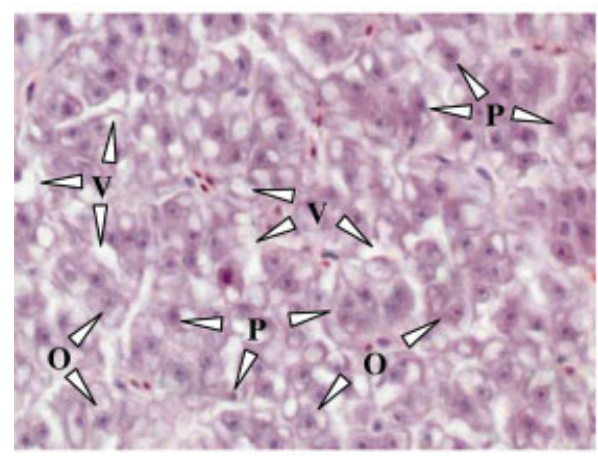

(e)

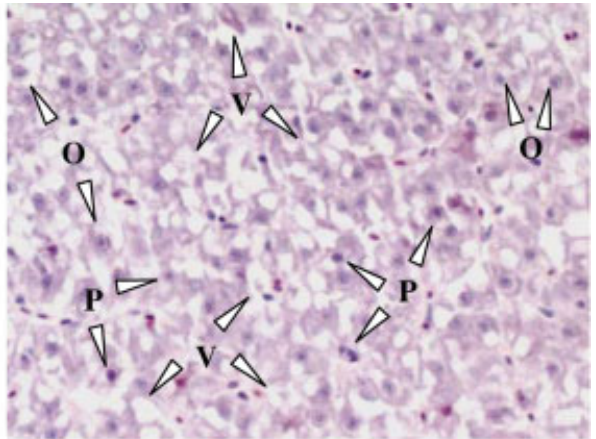

(b)

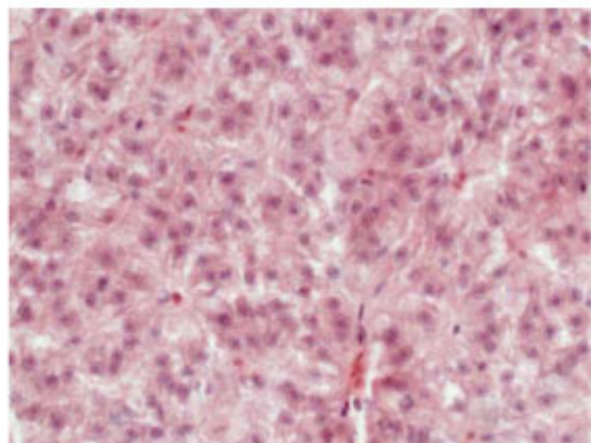

(d)

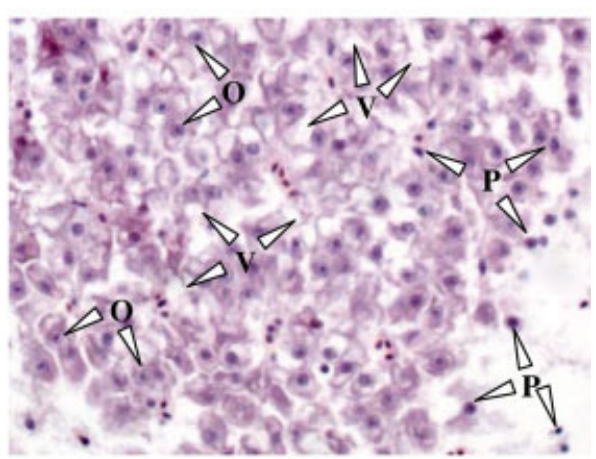

(f)

Fig. 4. Representative slices of medaka liver in control and exposure groups. $\mathrm{H} \& \mathrm{E}, \times 400$. (a) control; (b) Hg-III; (c) Se-III; (d) MS-I; (e) MS-II; (f) MS-III. The liver section from the control group showed normal gross structure and homogeneous cytoplasm without edema, vacuolation, or necrosis. Varying degrees of histopathological changes, such as basophilic cytoplasm, edema $(\mathrm{O})$, vacuoles $(\mathrm{V})$, and pyknotic nucleus $(\mathrm{P})$, were clearly observed in hepatocytes from single $\mathrm{Hg}$, single Se, and concurrent exposure (MS) groups. [Color figure can be viewed in the online issue, which is available at www.interscience.wiley.com.]

showed the morphological changes in hepatocytes from the Se-III group. The hepatocellular lesions seemed somewhat more serious than those in the single $\mathrm{Hg}$ groups, because the administration dose of $\mathrm{Na}_{2} \mathrm{SeO}_{3}$ was basically higher than that of MMC, based on their molar values. Although selenium is of much importance in the protection against mercury toxicity, the element is toxic when its concentrations are above the nutritional requirement (Hilton et al., 1980). In the MS-I group, appropriate selenium together with $\mathrm{MeHg}$ was accumulated in medaka body, with a $\mathrm{Hg}$ :Se molar ratio as close to 1 and so no obvious histopathological changes occurred in hepatocytes of the MS-I group [Fig. 4(d)]. In the MS-II and MS-III groups, the $\mathrm{Hg}$ :Se molar ratios were slightly small to that of the MS-I group, the interaction could not withstand against serious intoxication, and more severe lesions, including basophilic cytoplasm, edema, vacuoles, and pyknotic nucleus, were 


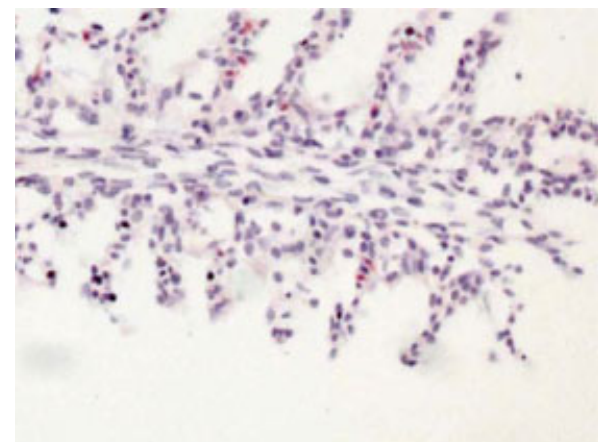

(a)

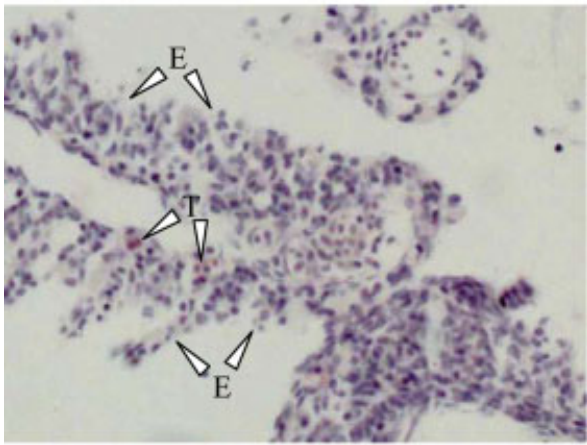

(c)

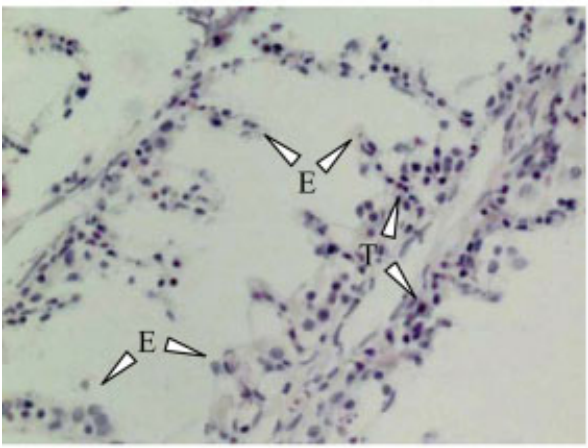

(e)

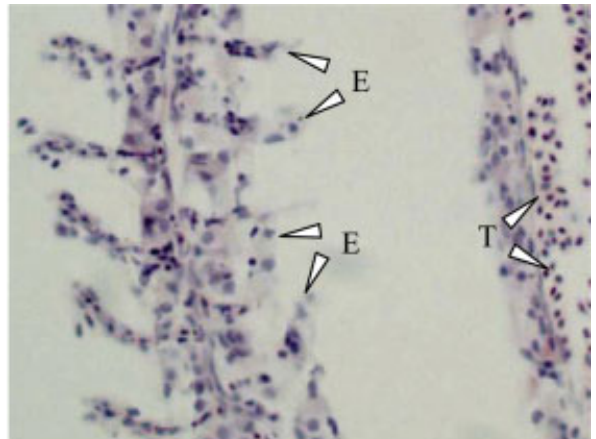

(b)

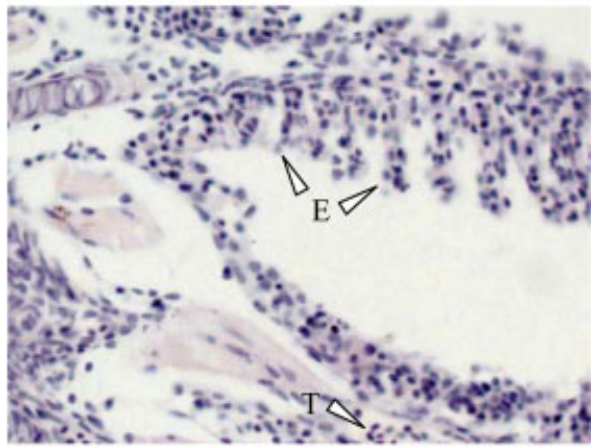

(d)

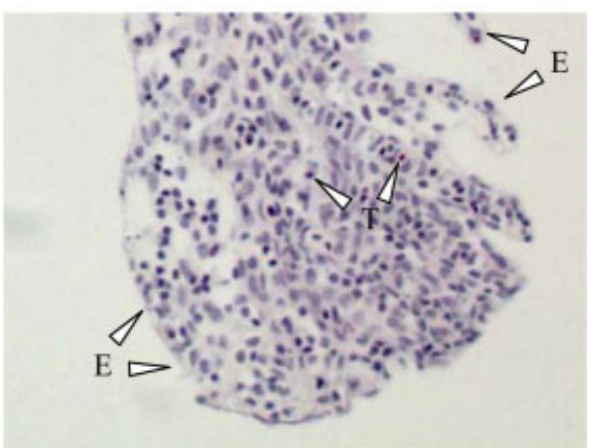

(f)

Fig. 5. Representative slices of medaka gill in control and exposure groups. H\&E, $\times 400$. (a) control; (b) Hg-III; (c) Se-III; (d) MS-I; (e) MS-II; (f) MS-III. No gross pathological changes were observed in the gill from the control group, and it has normal and clear configuration. Morphological changes in different degrees, such as necrosis of epithelial cells, pillar cells and mucous cells, telangiectasis $(T)$, and exfoliation of epithelial cells $(E)$, were distinctively observed in gill section from both single and concurrent exposure groups. [Color figure can be viewed in the online issue, which is available at www.interscience.wiley.com.]

observed in the MS-II and MS-III groups [Figs. 4(e,f)]. Especially for the MS-III group, extreme damage such as a large region of necrosis was observed in hepatocytes. This was explained by the fact that when the set $\mathrm{Hg}$ :Se molar ratio was high in concurrent exposure, the interaction could not afford protection against intoxication, on the contrary, high dose of MMC and $\mathrm{Na}_{2} \mathrm{SeO}_{3}$ administration enhanced the lesions in hepatocytes. The aforementioned morphological finding indicated a series of lesions in fish liver cells, which actually confirmed severe damage of $\mathrm{MeHg}$ and selenium to fish livers and ulteriorly influenced normal physiological activities. The result was fairly in agreement with those of other reports (Strmac and Braunbeck, 1999; Zaroogian et al., 2001).

II. Gill: The intoxication pattern of gill was similar to that of liver. No gross pathological changes were observed in the gill from the control group, and it had normal and clear configuration [Fig. 5(a)]. While morphological 
changes in different degrees, such as telangiectasis and exfoliation of epithelial cells, were distinctively observed in gill section from both single and concurrent exposure groups. For the single $\mathrm{Hg}$ exposure groups, widespread necrosis of epithelial cells, pillar cells, and mucous cells accompanied with telangiectasis and exfoliation of epithelial cells were common and dosedependent in gill sections [Fig. 5(b)]. For the single Se groups, a dose-related morphological change was also seen in gill sections. In addition, rather severe lesions, especially in the Se-III group [Fig. 5(c)], were found when compared with those in the Hg-III group [Fig. 5(b)], which was mainly due to the quite high dose of $\mathrm{Na}_{2} \mathrm{SeO}_{3}$ in Se-III (10-fold of MMC dose in $\mathrm{Hg}$-III). In the gill sections from the MS groups, extreme histopathological lesions were observed in three groups [Figs. $5(\mathrm{~d}-\mathrm{f})]$ and a dose-response relationship was found as well. Owing to the interaction of selenium with $\mathrm{MeHg}$, the lesion degree of gill in the MS-I group was slightly less than that in the Se-III group. In contrast to the liver in MS-I, the gill suffered from rather severe damage with slight protection. As well known, the respiratory system provides the most extensive interface of a fish with the aquatic environment, and thereby it is often the primary system to be affected by pollutants. The medaka gill in MS-I fast took high levels of selenium and $\mathrm{MeHg}$, and then the two chemicals directly did damage to the gill before selenium interacted with $\mathrm{MeHg}$ affording protection. With increase of selenium in gill, it might offer somewhat more powerful protection through interaction with $\mathrm{MeHg}$, while it could not stop or repair existing exposure-induced damage (Wang et al., 2001). Consequently, the medaka gill in MS-I also suffered damage to a certain degree, because of the limited protection arised by interaction. The highest level of MMC and $\mathrm{Na}_{2} \mathrm{SeO}_{3}$ administration caused maximum damage to gill in the MS-III group. The histological observation revealed that $\mathrm{MMC}$ and $\mathrm{Na}_{2} \mathrm{SeO}_{3}$ treatment had comparatively overt bad effects on medaka gills. Similar reports have been exemplified in previous reports (Karan et al., 1998; Peuranen et al., 2003).

\section{CONCLUSION}

The dose- and time-dependent increase of MeHg and selenium contents in the whole body of medaka was observed clearly in this study. Concurrent exposure to MMC with sodium selenite $\left(\mathrm{Na}_{2} \mathrm{SeO}_{3}\right)$ could not significantly influence the $\mathrm{MeHg}$ accumulation, but effectively promoted selenium accumulation in medaka body after a long exposure period. After exposure, the development inhibition, mortality and abnormality, such as bent spine, in different degrees, were observed in both single and concurrent exposure groups. The morphological findings suggested varying degrees of damages in medaka liver and gill cells, which actually con- firmed severe toxicities of $\mathrm{MeHg}$ and selenium to fish. The molar ratios of $\mathrm{MeHg}$ with selenium in medaka from three concurrent exposure groups were almost close to 1 . Selenium interacting with $\mathrm{MeHg}$ in the MS-I group presented a good protection against intoxication in the liver but a limited protection in the gill of medaka.

\section{REFERENCES}

Alli A, Jaffé R, Jones R. 1994. Analysis of organomercury compounds in sediments by capillary GC with atomic fluorescence detection. J High Resolut Chromatogr 17:745-748.

Aoshima K, Kasuya M. 1980. Interactions between mercuric chloride and sodium selenite on cultured rat cerebrum. Toxicol Lett 6:181-186.

Baatrup E. 1991. Structural and functional effects of heavy metals on the nervous system, including sense organs, of fish. Comp Biochem Physiol C 100:253-257.

Berntssen MHG, Aatland A, Handy RD. 2003. Chronic dietary mercury exposure causes oxidative stress, brain lesions, and altered behaviour in Atlantic salmon (Salmo salar) parr. Aquat Toxicol 65:55-72.

Cai Y, Tang G, Jaffé R, Jones R. 1997. Evaluation of some isolation methods for organomercury determination in soil and fish samples by capillary gas chromatography-atomic fluorescence spectrometry. Int J Environ Anal Chem 68:331-345.

Cuvin-Aralar MLA, Furness RW. 1991. Mercury and selenium interaction: A review. Ecotoxicol Environ Saf 21:348364.

Dolbec J, Mergler D, Larribe F, Roulet M, Lebel J, Lucotte M. 2001. Sequential analysis of hair mercury levels in relation to fish diet of an Amazonian population, Brazil. Sci Total Environ 271:87-97.

Donangelo CM, Dorea JG. 1998. Mercury and lead exposure during early human life as affected by food and nutritional status. Environ Nutr Interact 2:169-186.

Goede AA, Wolterbeek HT. 1994. Have high selenium concentrations in wading birds their origin in mercury? Sci Total Environ 144:247-253.

Hammerschmidt CR, Sandheinrich MB, Wiener JG, Rada RG. 2002. Effects of dietary methylmercury on reproduction of fathead minnows. Environ Sci Technol 36:877-883.

He B, Liang LN, Jiang GB. 2002. Distributions of arsenic and selenium in selected Chinese coal mines. Sci Total Environ 296:19-26.

Heath AG. 1995. Uptake, accumulation, biotransformation, and excretion of xenobiotics. In: Heath AG, editor. Water Pollution and Fish Physiology. Boca Raton, FL: CRC Lewis Publisher. pp 79-123.

Hilton JW, Hodson PV, Slinger SJ. 1980. The requirement and toxicity of selenium in rainbow trout (Salmo gairdneri). J Nutr 110:2527-2535.

Houck A, Cech JJ Jr. 2004. Effects of dietary methylmercury on juvenile Sacramento blackfish bioenergetics. Aquat Toxicol 69:107-123. 
Inza B, Ribeyre F, Boudou A. 1998. Dynamics of cadmium and mercury compounds (inorganic mercury or methylmercury): Uptake and depuration in Corbicula fluminea. Effects of temperature and $\mathrm{pH}$. Aquat Toxicol 43:273-285.

Karan V, Vitorovic S, Tutundîzic V, Poleksic V. 1998. Functional enzymes activity and gill histology of carp after copper sulfate exposure and recovery. Ecotoxicol Environ Saf 40:49-55.

Koeman JH, Peeters WH, Koudstaal-Hol CH, Tjioe PS, Goeij JJD. 1973. Mercury-selenium correlations in marine mammals. Nature 245:385-386.

Komsta-Szumska E, Chmielnicka J. 1977. Binding of mercury and selenium in subcellular fractions of rat liver and kidneys following separate and joint administration. Arch Toxicol 38:217-228.

Kondo K. 2000. Congenital Minamata disease: Warnings from Japan's experience. J Child Neurol 15:458-464.

Lebel J, Mergler D, Branches F, Lucotte M, Amorim M, Larribe F, Dolbec J. 1998. Neurotoxic effects of low-level methylmercury contamination in the Amazonian Basin. Environ Res A 79:20-32.

MSDS (Material Safety Data Sheet) information. 2004. Available at http://ptcl.chem.ox.ac.uk/MSDS/.

Myers GJ, Davidson PW, Cox C, Shamlaye C, Cernichiari E, Clarkson TW. 2000. Twenty-seven years studying the human neurotoxicity of methylmercury exposure. Environ Res 83:275-285.

NRC (National Research Council). 2000. Toxicological Effects of Methylmercury. Washington, DC: National Academy Press.
Peuranen S, Keinänen M, Tigerstedt C, Vuorine PJ. 2003. Effects of temperature on the recovery of juvenile grayling (Thymallus thymallus) from exposure to $\mathrm{Al}+\mathrm{Fe}$. Aquat Toxicol 65: 73-84.

Shi JB, Liang LN, Jiang GB. 2005. Simultaneous determination of methylmercury and ethylmercury in rice by capillary gas chromatography coupled on-line with atomic fluorescence spectrometry. J AOAC Int 88:665-669.

Strmac M, Braunbeck T. 1999. Effects of triphenyltin acetate on survival, hatching success, and liver ultrastructure of early life stages of zebrafish (Danio rerio). Ecotoxicol Environ Saf 44:25-39.

Wang A, Barber D, Pfeiffer CJ. 2001. Protective effects of selenium against mercury toxicity in cultured Atlantic spotted dolphin (Stenella plagiodon) renal cell. Arch Environ Contam Toxicol 41:403-409.

Wu SA, Zhang GL, Xu J, Wang XZ. 1994. Environmental epidemiological study on the chronic methylmercury poisoning along the Songhua River. China Environ Sci 14:268-272.

Xu HB, Fan HH. 1991. Selenium. In: Wang K, editor. Trace Elements in Life Science. Beijing: China Meterage Press. pp189248.

Zaroogian G, Gardner G, Horowitz DB, Gutjahr-Gobell R, Haebler R, Mills L. 2001. Effect of $17 \beta$-estradiol, $o, p^{\prime}$-DDT, octylphenol and $p, p^{\prime}$-DDE on gonadal development and liver and kidney pathology in juvenile male summer flounder (Paralichthys dentatus). Aquat Toxicol 54:101-112. 